\title{
Study on the Pressure Dependence of Boiling Point, Flashpoint, and Lower Flammability Limit at Low Ambient Pressure
}

\author{
Chao Ding, ${ }^{\dagger}$ Yaping He, ${ }^{\dagger}$ Jiusheng Yin, ${ }^{\S}$ Wei Yao, ${ }^{\|}$Dechuang Zhou, ${ }^{\dagger}$ and Jian Wang* ${ }^{\dagger}$ \\ ${ }^{\dagger}$ State Key Laboratory of Fire Science, University of Science and Technology of China, Hefei 230026, China \\ ${ }^{\ddagger}$ School of Computing, Engineering and Mathematics, University of Western Sydney, Locked Bag 1797, Penrith 2751, Australia \\ ${ }^{\S}$ Institute of Public Safety Research, Tsinghua University, Beijing 100084, China \\ "LHD, Institute of Mechanics, Chinese Academy of Sciences, Beijing 100190, China
}

ABSTRACT: The boiling point, flashpoint, and flammability limit are key parameters to evaluate the combustion behavior of flammable liquids. In this study, the boiling point $\left(T_{\mathrm{B}}\right)$, the flashpoint $\left(T_{\mathrm{F}}\right)$, and the lower flammable limit (LFL) of two multiplecomponent fuels (diesel and Jet $\mathrm{A}$ ) and two single-component fuels ( $n$-hexanol and $n$-decane) were measured at low pressures ranging from 35 to $101 \mathrm{kPa}$. The dependences of $T_{\mathrm{B}}, T_{\mathrm{F}}$, and LFL on pressure have been theoretically derived to explain the experimental measurements. In addition to the observation that both boiling point and flashpoint decrease with decreasing pressure, the measurements also revealed that the open-cup and closed-cup flashpoints decrease at different rates. The lower flammability limit, on the other hand, was shown to increase with the decreasing of pressure. The measurements of the lower flammability limit versus pressure were well correlated with different theoretical formulas proposed in the literature and the current study. The relationships among $T_{\mathrm{B}}, T_{\mathrm{F}}$, and LFL at low pressure are also discussed and verified against the measurements.

\section{INTRODUCTION}

In recent years much attention has been given to the combustion, or the consequence of ignition, of flammable liquids such as $n$-heptane and ethanol under hypobaric conditions. ${ }^{1,2}$ It was found that the buoyancy controlled combustion flames under the same burning rate were elongated at lower ambient pressure or high altitude conditions, resulting in an increased fire hazard. This result places an emphasis on the prevention of ignition as a fire safety measure. Therefore, determination of the variation of ignition parameters, such as the boiling point $\left(T_{\mathrm{B}}\right)$, the flashpoint $\left(T_{\mathrm{F}}\right)$, and the lower flammability limit (LFL) of flammable liquids at lower pressure or high altitudes is of vital importance for the fire safety design of usage, storage, and transportation of liquid fuels (e.g., Jet-A for airplanes, diesel and gasoline for land vehicles). It is noted at this point that the transportation of land vehicle fuels is not limited to the land surface, since airborne transportation of land vehicle fuels may be necessary for emergency rescue and other applications.

Based on the experimental study using an equilibrium closed bomb apparatus, Kong et al. ${ }^{3}$ and Shepherd et al. ${ }^{4}$ attempted to explain the flashpoint and boiling point in terms of ignition energy and other physical and chemical properties of Jet A. Shepherd et al. ${ }^{5}$ and Nestor ${ }^{6}$ provided a linear relationship between the flashpoint and the pressure by measuring the flashpoint of aviation kerosene under different altitudes from 0 to $10700 \mathrm{~m}$. The lower flammability limit of gases and vapors has been investigated at standard temperature and atmospheric pressure, ${ }^{7,8}$ as well as at elevated temperatures and pressures. $^{9-11}$ However, some discrepancies exist between the results obtained by different investigators. For example, Liu et al. ${ }^{9}$ showed the presence of a nonlinear dependence of the flammability limit on pressure, but the results by Schoor et al. ${ }^{11}$ showed a linear one. The classical framework by Kanury ${ }^{12}$ to link the boiling point, flashpoint, and the lower flammability of liquid fuels is applicable only for standard atmospheric condition. However, whether it can be extended to a low pressure environment is still unknown. No universal model capable of predicting $T_{\mathrm{B}}, T_{\mathrm{F}}$, and LFL for a wide range of pressure circumstances is publicly available currently.

The previous studies on boiling point, flashpoint, and flammability limit focused mainly on discrete pressure environemnts, such as the standard atmosphere pressure, and did not intend to reveal their pressure dependences. Furthermore, only a narrow range of flammable liquids were reported. An accurate description of the dependence of boiling point, flashpoint, and flammability limit on pressure over a wider range of pressure, particularly under substandard atmospheric, or hypobaric pressure is needed. Such knowledge would provide more insight for the minimization of ignition probability and hence the reduction of fire hazard related to liquid fuel storage and transportation by aircrafts and ground vehicles operating at high-altitude. For example, based on the International Flammable and Combustible Liquids Code, ${ }^{13}$ Chao et al. ${ }^{14}$ classified fire hazard classification at different altitudes using the concept of the closed-cup flashpoint.

The present work consists of the experimental determination of $T_{\mathrm{B}}$ and $T_{\mathrm{F}}$ for four flammable liquids and the lower flammability limit of their vapors in a low-pressure chamber with a pressure range from 35 to $101 \mathrm{kPa}$. Two of the flammable liquids are multiple-components, namely diesel and Jet $\mathrm{A}$, while the other two are single-components, namely $n$-hexanol and $n$-decane. Theoretical analysis was conducted to describe the pressure effect on $T_{B}, T_{F}$, and LFL. The relationships among

Received: August 27, 2014

Revised: January 13, 2015

Accepted: January 20, 2015

Published: January 20, 2015 
the boiling point, the flashpoint, and the lower flammable limit at low ambient pressure were also analyzed.

\section{THEORY}

2.1. Boiling Point vs Pressure. According to the Clausius-Clapeyron relation, ${ }^{15}$ the vapor pressure of the fuel $P_{\text {fuel }}$ above the liquid surface is a function of the liquid surface temperature $T_{\text {fuel }}$

$$
P_{\text {fuel }}=P_{1} \exp \left[\frac{h_{\mathrm{fg}}}{R}\left(\frac{1}{T_{1}}-\frac{1}{T_{\text {fuel }}}\right)\right]
$$

The temperature corresponding to the liquid saturation vapor pressure when it is equal to the ambient pressure is known as the boiling point. ${ }^{16}$ So the following equation can be obtained

$$
P=P_{1} \exp \left[\frac{h_{\mathrm{fg}}}{R}\left(\frac{1}{T_{1}}-\frac{1}{T_{\mathrm{B}}}\right)\right]
$$

which may be rewritten in the following form

$$
\frac{1}{T_{\mathrm{B}}}=\left(-\frac{R}{h_{\mathrm{fg}}}\right) \ln P+\left(\frac{1}{T_{1}}+\frac{R}{h_{\mathrm{fg}}} \ln P_{1}\right)
$$

2.2. Lower Flammability Limit and Flashpoint vs Pressure. From the studies by Vanderstraeten et al. ${ }^{10}$ for elevated pressure, the dependence of the LFL on the pressure of methane-air mixtures can be expressed as

$$
\mathrm{LFL}=m\left(P^{2}+b P+c\right)
$$

where $m, b$, and $c$ are coefficients. On the other side, Schoor and Verphaetsen ${ }^{11}$ showed a linear relationship between pressure and the flammability limit of methane-hydrogen-air mixtures

$$
\mathrm{LFL}=u(P+v)
$$

where $u$ and $v$ are constants. The above two models can be used to derive relationships between flashpoint and pressure as in the following.

The fuel-air mass ratio is related to the mole values and molecular weights of fuel and air by

$$
f=\frac{n_{\text {fuel }} M_{\text {fuel }}}{n_{\text {air }} M_{\text {air }}}
$$

where $M_{\text {fuel }}$ is the molecular weight of the fuel, $n_{\text {fuel }}$ is the mole value of fuel, $M_{\text {air }}$ is the molecular weight of air, and $n_{\text {air }}$ is the mole of air. In terms of the total pressure of the gas mixture and the fuel vapor partial pressure

$$
f=\frac{P_{\text {fuel }}}{P-P_{\text {fuel }}} \frac{M_{\text {fuel }}}{M_{\text {air }}}
$$

Assuming that eq 7 also holds at flashpoint, we rearrange it to yield

$$
P_{\mathrm{F}}=\frac{P}{\left(1+\frac{1}{f} \frac{M_{\text {fuel }}}{M_{\text {air }}}\right)}
$$

Substituting eq 8 into eq 1 and rearranging, at flashpoint condition it yields

$$
P=P_{1} \cdot\left(1+\frac{1}{f_{\mathrm{F}}} \frac{M_{\text {fuel }}}{M_{\text {air }}}\right) \exp \left[\frac{h_{\mathrm{fg}}}{R}\left(\frac{1}{T_{1}}-\frac{1}{T_{\mathrm{F}}}\right)\right]
$$

The lower flammability limit is known as the minimum fuel concentration in the gas mixture, at which the flammable combustion occurs. Let $f_{\mathrm{LFL}}$ denote the corresponding mass fraction. From eq 7, the following identity holds:

$$
\mathrm{LFL}=\min \left(\frac{P_{\text {fuel }}}{P}\right)=\min \left(\frac{n_{\text {fuel }}}{n_{\text {fuel }}+n_{\text {air }}}\right)=\left(\frac{1}{1+\frac{M_{\text {fuel }}}{M_{\text {air }} f_{\text {LFL }}}}\right)
$$

Assuming that the fuel-air mass fraction at the flashpoint is equal to the lower flammability fuel-air mass fraction, using eqs 10 and 4 or 5 , eq 9 can be rearranged to

$$
P^{3}+b P^{2}+c P=\frac{P_{1}}{m} \exp \left[\frac{h_{\mathrm{fg}}}{R}\left(\frac{1}{T_{1}}-\frac{1}{T_{\mathrm{F}}}\right)\right]
$$

or

$$
P^{2}+v P=\frac{P_{1}}{u} \exp \left[\frac{h_{\mathrm{fg}}}{R}\left(\frac{1}{T_{1}}-\frac{1}{T_{\mathrm{F}}}\right)\right]
$$

which can then be written in the following forms:

$$
\frac{1}{T_{\mathrm{F}}}=-\frac{R}{h_{\mathrm{fg}}} \ln \left(P^{3}+b P^{2}+c P\right)+\left[\frac{1}{T_{1}}+\frac{R}{h_{\mathrm{fg}}} \ln \left(\frac{P_{1}}{m}\right)\right]
$$

or

$$
\frac{1}{T_{\mathrm{F}}}=-\frac{R}{h_{\mathrm{fg}}} \ln \left(P^{2}+v P\right)+\left[\frac{1}{T_{1}}+\frac{R}{h_{\mathrm{fg}}} \ln \left(\frac{P_{1}}{u}\right)\right]
$$

Equations $12 \mathrm{a}$ and $12 \mathrm{~b}$ reveal the linear relationships between the reciprocal of flashpoint and the natural log of polynomials of pressure, based on the models expressed in eqs 4 or 5 respectively.

\section{EXPERIMENTAL FACILITIES AND MEASUREMENTS}

Experiments were conducted in accordance with the measurement standards ${ }^{17-20}$ for boiling point and flashpoint at seven static pressures, i.e., $101,95,85,75,65,55,45$, and $35 \mathrm{kPa}$. The measured pressure range corresponds to the latitude from 0 to $8117 \mathrm{~m}$. Figure la shows the $3 \times 2 \times 2 \mathrm{~m}$ lowpressure chamber used in this study. The pressure of the chamber can be controlled via a vacuum pump and a controlling system. The working pressure range of the chamber is 26.4-101.3 kPa. The chamber pressure can be measured and controlled with a resolution of $0.1 \mathrm{kPa}$.

3.1. Measurement of Boiling Point. A portable apparatus shown in Figure $1 \mathrm{~b}$ was designed in reference to an Othmertype ebulliometer ${ }^{17}$ to measure the boiling point in this study. The apparatus consists of a boiling pot which contains the sample fuel and can be heated using an adjustable electrical power heating. The sample fuel temperature is measured by a K-type thermocouple which was placed in the middle of the measured liquid in the boiling pot.

In the test, the final stabilized temperature of the liquid fuel during the gradual heating of the pot is determined to the boiling point. As the fuel temperature increases, the fuel vapor bubbles will appear in the boiling pot; as a greater amount of heat is added, the boiling becomes more violent; however, the fuel temperature stops rising. 


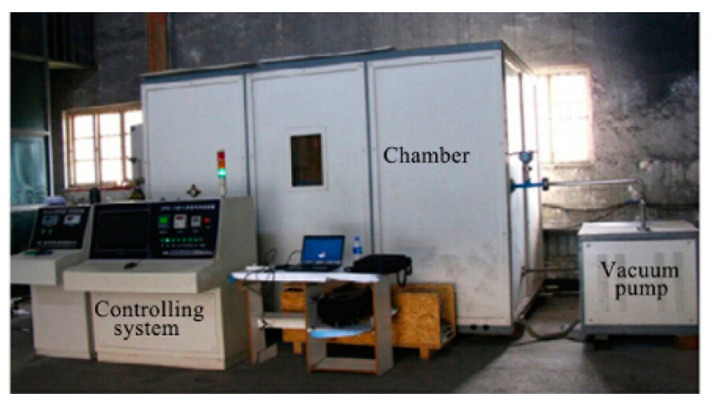

(a)

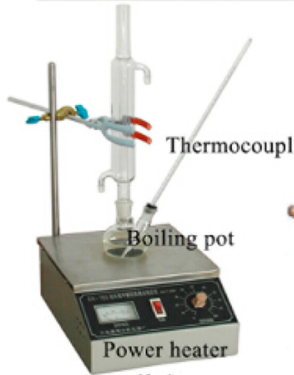

(b)

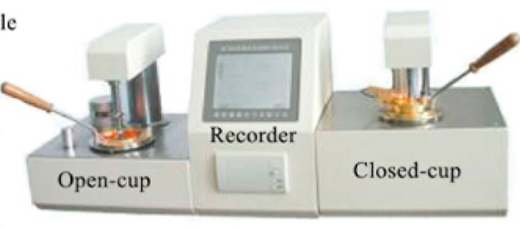

(c)
Figure 1. Schematic of the experimental setup: (a) the low-pressure chamber, (b) $T_{\mathrm{B}}$ tester, and (c) $T_{\mathrm{F}}$ tester.

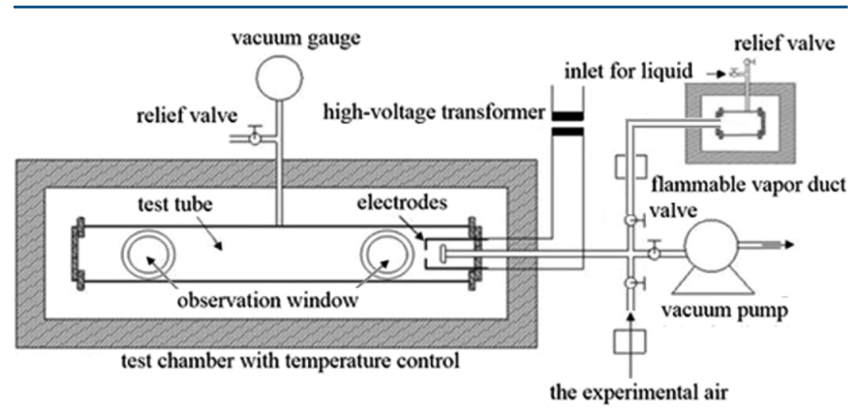

Figure 2. Schematic of the apparatus for measuring the LFL.

3.2. Measurement of the Lower Flammability Limit. A test tube shown in Figure 2 was designed and used in accordance with EN $1839^{18}$ to measure the lower flammability limit of the four fuel vapors. The test tube is a horizontal stainless steel cylinder of $500 \mathrm{~mm}$ in length and $80 \mathrm{~mm}$ in diameter. Two quartz glass windows for observation are installed in the test tube. The tube and other accessories including an evaporator and a vapor duct are sealed in a chamber. The pressure of the chamber can be regulated from $10 \mathrm{kPa}$ to the standard atmospheric pressure with a controlling accuracy of $\pm 66 \mathrm{~Pa}$. In this apparatus the gas mixture inside the tube is ignited using a direct current (DC) arc igniter. The igniter was connected to the high-voltage transformer capable of providing $10000 \mathrm{~V}$ and $23 \mathrm{~mA}$ output, as shown in Figure 2. The induction spark is drawn between two electrodes located $60 \mathrm{~mm}$ from one end of the tube. The electrodes are $4 \mathrm{~mm}$ apart. The mixture is considered flammable when the spark creates a flame which detaches from the electrodes.

Before each test the tube is thoroughly purged 3 times by clean air with $99.99 \%$. The fuel vapor is produced by heating the liquid fuel with a thermostatic facility to $573 \mathrm{~K}$. The detailed measuring process has been documented in ref 18 . The relative error of the gas mixture concentration is estimated to be less than $3 \%$. During the test, the vapor partial pressure is gradually increased at a rate of $133 \mathrm{~Pa} \mathrm{~s}^{-1}$ until the flame detachment is observed. The lower flammability limit is the lowest vapor concentration at which the flame detachment is observed. Each test was repeated three times to ensure reproducible results within permitted error specified in EN $1839 .^{18}$

3.3. Measurement of Flashpoint. The flashpoints of liquid fuels were measured respectively using a closed-cup device and an open-cup device (Figure 1c) in accordance with the standard test methods of ASTM D $93^{19}$ and ASTM D $92 .{ }^{20}$ The fuel specimen is placed in a container, and its temperature is increased by a metal heating bath. The fuel vapor is periodically exposed to a flame, and observation was made for the onset of combustion. The lowest vapor temperature at which ignition was observed is taken as the flashpoint. Each pressure test was repeated three times to ensure repeatability. The repeatability and reproducibility of the results met the specifications in the standards. ${ }^{19,20}$

\section{ANALYSIS AND DISCUSSION OF EXPERIMENTAL RESULTS}

All experiments were conducted in the low pressure chamber at the pressures described in section 3 . Under each pressure condition the measurements of boiling point, lower flammability limit, and flashpoint were repeated three times. Tables A1-A4 in the Appendix list the measurement results of boiling point, lower flammability limit, open-cup flashpoint, and closedcup flashpoint of all experiments. Unless otherwise specified, the experimental results presented in the following subsections are the average of the three repeated tests under the same conditions.

4.1. Boiling Point. The boiling point is the temperature when the liquid is boiling for the pure substance ( $n$-hexanol and $n$-decane). For the mixed fuels (diesel and Jet A), there may exist multiple boiling points corresponding to the multiple constituents of the fuel. The boiling point of mixed liquids is taken to be the temperature at the first occurrence of boiling in the current experiments. The recorded fuel temperature variations with time during the heating process of the repeated test under the same pressure condition of $101 \mathrm{kPa}$ for two different fuels are presented in Figure 3a. As can be seen from Figure 3a, the three reproducible experimental data are in good agreement at some extent. Figure $3 \mathrm{~b}$ presents the measured typical fuel temperatures of decane and Jet $\mathrm{A}$ under three pressure conditions. The changes in boiling points of the two fuels are clearly revealed. It also can be seen from Figure $3 b$, for Jet A (multiple-component fuels), the decreasing of the pressure does not affect the increasing for the temperature, but for $n$-decane (single-component fuels), the increasing rate of the temperature is shown to decrease with the decreasing of the pressure.

Note that the initial temperature inside the low pressure chamber was in equilibrium with the ambient. Except for the heat release by the experimental equipment, no additional heating or cooling was administered.

The boiling point measured at different pressures for the four flammable liquids are shown in Figure 4 by plotting the reciprocal of boiling point versus the logarithm of pressure according to eq 3. The symbols in this figure represent the average of the three repeated test results at given pressures, and the error bars indicate the variation of the repeated tests. The corresponding error in the measured boiling point is on the order of $\pm 1 \mathrm{~K}$ (see Table Al in the Appendix).

Table 1 lists the properties of the fuels, the theoretical values of the slope $\left(-R / h_{\mathrm{fg}}\right)$, and the intercept $\left(1 / T_{1}+\ln P_{1} R / h_{\mathrm{fg}}\right)$ in eq 3 , as well as the fitted values of the slope and the intercept 


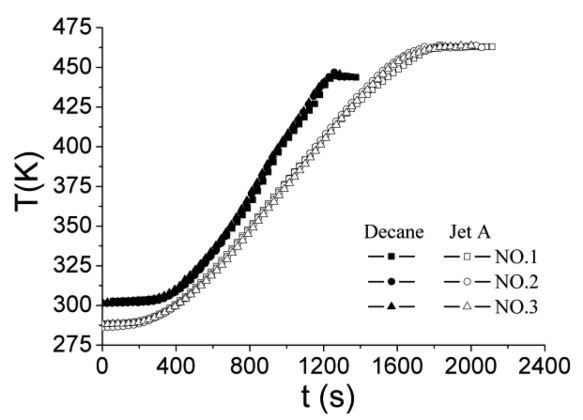

(a)

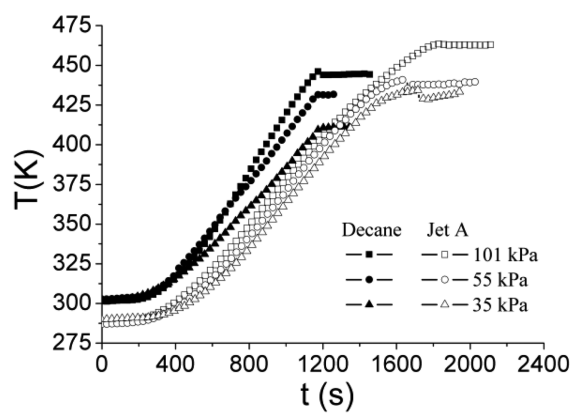

(b)

Figure 3. Measured typical fuel temperatures as functions of time during the heating process: (a) the repeated test under the same pressure condition of $101 \mathrm{kPa}$; (b) under different ambient pressures.

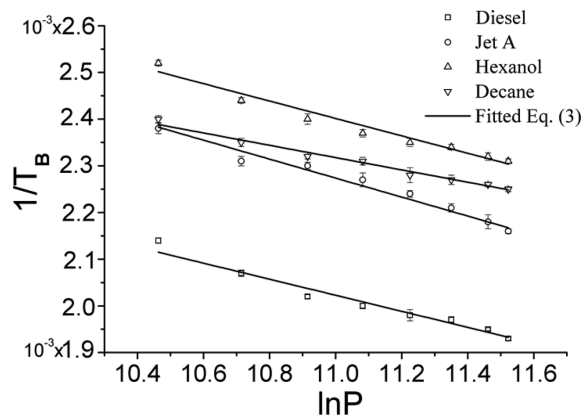

Figure 4. Boiling point versus pressure for the four flammable liquids.

for the regression lines in Figure 4. The correlation coefficients between the regression lines and the experimental data are also included in Table 1 . It can be seen that the fitted values for the slope and the intercept are in good agreement with the theoretical values based on the material properties of the fuels. The slight deviation is probably due to the neglect of the influence of pressure on $h_{\mathrm{fg}}$ and $P_{1}$.

The results presented in Figure 4 and Table 1 uncover that, at a given pressure within the pressure range of $35-101 \mathrm{kPa}$, diesel has the highest boiling point among the four fuels studied, Jet A the second highest, and hexanol the lowest. Jet A has the highest rate of change in boiling point with pressure and decane the lowest. It is possible that, at some pressure point less than $35 \mathrm{kPa}$, the boiling point of decane may exceed that of Jet A.

4.2. Lower Flammability Limit. In a typical test of the LFL, the flash fire starting from the ignition side of the test tube propagated to the other side in about $2 \mathrm{~s}$. Figure 5 shows the images recorded in a test with decane at $95 \mathrm{kPa}$ pressure. Ignition can be seen through the observation window at the left at $t=0 \mathrm{~s}$. The propagation finished at about $t=2 \mathrm{~s}$.

The averaged lower flammability limit over three repeated measurements at various pressures are plotted in Figure 6 for

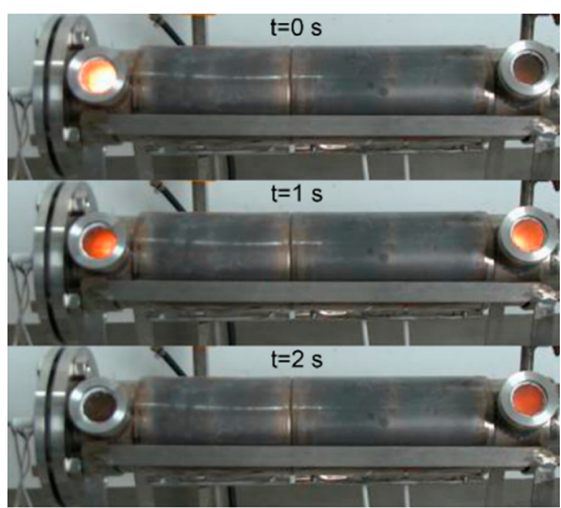

Figure 5. Phenomena of the lower flammability limit of decane at $95 \mathrm{kPa}$.

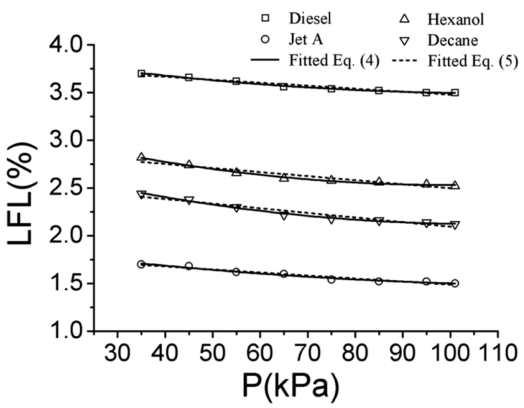

Figure 6. Lower flammability limit versus pressure for the four flammable vapors.

the four liquid fuels. The maximum error in the three repeated measurements of LFL is $\pm 5 \%$. The line plots are the linear and parabolic regression curves in the forms of eqs 4 and 5, respectively. The regression coefficients and the corresponding correlation coefficients are shown in Table 2 . It can be seen that the results of the experiment are in better agreement with the

Table 1. Theoretical and Fitted Values of the Slope and Intercept in Figure 4

\begin{tabular}{|c|c|c|c|c|c|c|c|c|}
\hline \multirow[b]{2}{*}{ fuel material } & \multirow[b]{2}{*}{ chemical formula } & \multirow[b]{2}{*}{$h_{\mathrm{fg}}^{a}\left(\mathrm{~J} \mathrm{~mol}^{-1}\right)$} & \multirow[b]{2}{*}{$P_{1}^{b}(\mathrm{~Pa})$} & \multicolumn{2}{|c|}{ theoretical values } & \multicolumn{3}{|c|}{ fitted values } \\
\hline & & & & slope $\left(-R / h_{\mathrm{fg}}\right)$ & intercept $\left(1 / T_{1}+\ln P_{1} R / h_{f g}\right)$ & slope & intercept & $R_{\mathrm{c}}$ \\
\hline diesel & $\mathrm{C}_{12} \mathrm{H}_{23}$ & & & & & $-1.7 \times 10^{-4}$ & 0.004 & 0.96 \\
\hline Jet A & $\mathrm{C}_{12} \mathrm{H}_{22}$ & & & & & $-2.0 \times 10^{-4}$ & 0.005 & 0.97 \\
\hline hexanol & $\mathrm{C}_{6} \mathrm{H}_{14} \mathrm{O}$ & $4.6 \times 10^{4}$ & 152.7 & $-1.8 \times 10^{-4}$ & 0.005 & $-1.9 \times 10^{-4}$ & 0.005 & 0.97 \\
\hline decane & $\mathrm{C}_{10} \mathrm{H}_{22}$ & $5.9 \times 10^{4}$ & 62.8 & $-1.4 \times 10^{-4}$ & 0.003 & $-1.3 \times 10^{-4}$ & 0.003 & 0.98 \\
\hline
\end{tabular}

${ }^{a_{\mathrm{T}}}$ The data for $h_{\mathrm{fg}}$ was extracted from NIST (http://physics.nist.gov). ${ }^{b}$ The data for $P_{1}$ was calculated by the Antoine equation: $\ln P=A-B /(T+C)$, where $A, B$, and $C$ are constants obtain from the Open Chemistry Database (http://pubchem.ncbi.nlm.nih.gov). 
Table 2. Fitting Result and Coefficients of the Regression Lines in Figure 6

\begin{tabular}{|c|c|c|c|c|c|c|c|}
\hline \multirow[b]{2}{*}{ fuel material } & \multicolumn{4}{|c|}{$\mathrm{LFL}=m\left(P^{2}+b P+c\right)^{a}$} & \multicolumn{3}{|c|}{$\mathrm{LFL}=u(P+v)$} \\
\hline & $m$ & $b$ & $c$ & $R_{\mathrm{c}}$ & $u$ & $v$ & $R_{\mathrm{c}}$ \\
\hline diesel & $3.7 \times 10^{-11}$ & $-2.2 \times 10^{5}$ & $1.1 \times 10^{11}$ & 0.97 & $-3.1 \times 10^{-6}$ & $-1.2 \times 10^{6}$ & 0.94 \\
\hline Jet A & $2.6 \times 10^{-11}$ & $-2.6 \times 10^{5}$ & $7.2 \times 10^{10}$ & 0.96 & $-3.2 \times 10^{-6}$ & $-5.7 \times 10^{5}$ & 0.95 \\
\hline hexanol & $6.8 \times 10^{-11}$ & $-1.9 \times 10^{5}$ & $4.7 \times 10^{10}$ & 0.97 & $-4.2 \times 10^{-6}$ & $-6.9 \times 10^{5}$ & 0.90 \\
\hline decane & $6.3 \times 10^{-11}$ & $-2.1 \times 10^{5}$ & $4.5 \times 10^{10}$ & 0.96 & $-4.8 \times 10^{-6}$ & $-5.3 \times 10^{5}$ & 0.93 \\
\hline
\end{tabular}

${ }^{a_{\text {The }}}$ unit of pressure $P$ is $\mathrm{Pa}$.
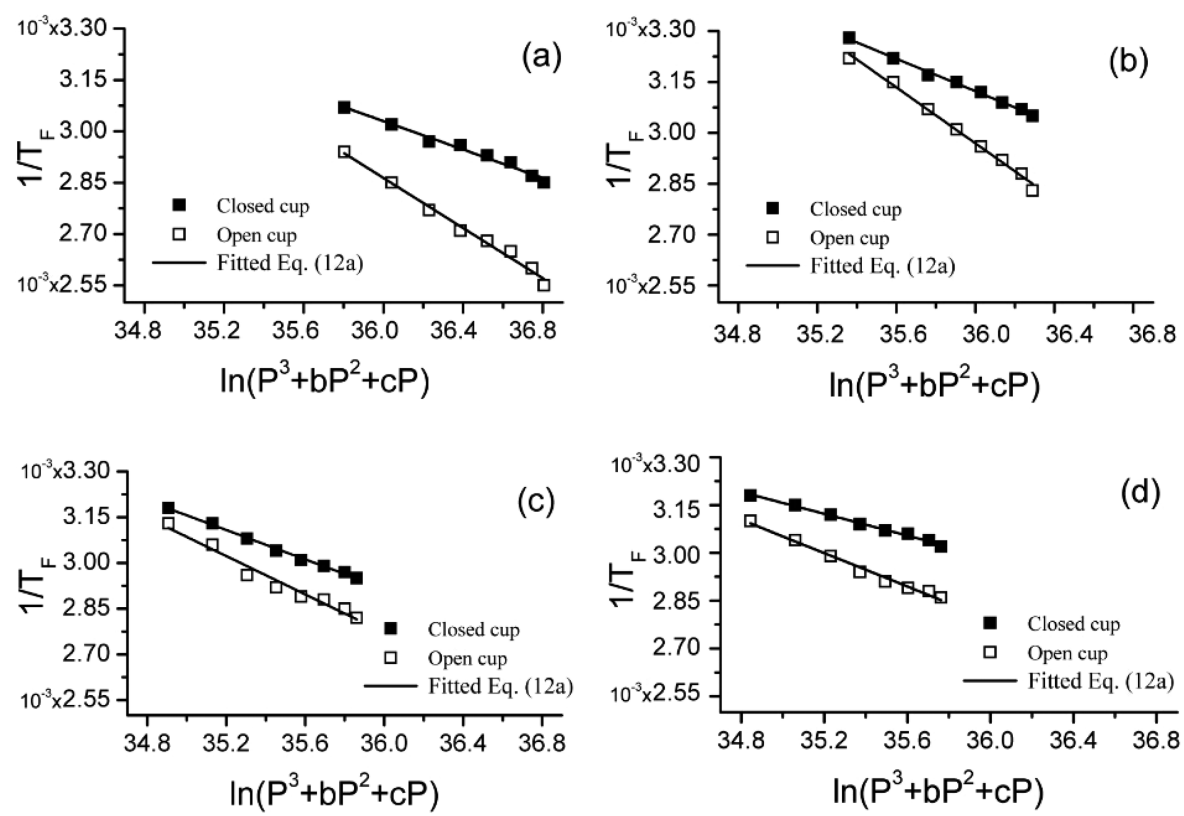

Figure 7. Flashpoint versus pressure: (a) diesel, (b) Jet A, (c) hexanol, and (d) decane.

quadratic relationship than with the linear relationship between the lower flammability limit and the pressure. From Figure 6, the lower flammability limit increases as the pressure decreases for all the flammable liquids studied herein. In other words, higher fuel concentration is needed for combustion to occur at lower pressure. This can be principally explained by the statistical mechanics and chemical kinetics. At a constant temperature, pressure reduction causes reduction in the molecule density. The probability of collision between the fuel and oxygen molecules per unit volume is reduced. In order to increase this probability such that the exothermic reaction can be triggered and sustained, a relatively larger amount of fuel molecules or higher fuel concentration is required, implying an increased lower flammability limit. From the viewpoint of fire safety, increasing the lower flammability limit at lower pressures leads to reduced fire ignition hazards.

The results in Figure 6 and Table 2 reveal that, under the pressure range tested in the current study, diesel has the highest lower flammability limit, followed by hexanol, and Jet A the lowest. The rates of change in LFL with pressure for the four fuels are similarly small.

4.3. Flashpoint. The reciprocal of the measured flashpoints of the four flammable liquids are plotted versus $\ln \left(P^{3}+b P^{2}+c P\right)$ in Figure 7 together with the fitted functions as given by eq $12 \mathrm{a}$. The plotted data are the average of three repeated test results with flashpoint measurement error of $\pm 1 \mathrm{~K}$ (see Tables A3 and A4 in the Appendix). It is easy to find that the open-cup flashpoints of the four flammable liquids are generally higher than their closed-cup counterparts at a given pressure for the pressure range encountered in the current study. Therefore, it will be prudent and conservative to use closed-cup flashpoints for fire hazard classification and fire safety design. Furthermore, all flashpoints decrease nonlinearly with decreasing pressure. This result is in contrast to that by Shepherd et al. ${ }^{5}$ and Nestor, ${ }^{6}$ who showed a linear relationship between the flashpoint of aviation fuel and pressure. In particular, according to the research by Nestor, ${ }^{6}$ the flashpoint of a turbine fuel decrease linearly by $1{ }^{\circ} \mathrm{C}$ for every $3.65 \mathrm{kPa}$ decrease in pressure. On the other hand, the current study of the four flammable liquids has shown that $\mathrm{d} T_{\mathrm{F}} / \mathrm{d} P$ is not a constant but is pressure dependent. It also can be found that the slope of the open-cup results is steeper than that of the closed-cup, i.e., the open-cup flashpoint decreases faster than the closed-cup flashpoint with decreasing pressure. In the research by Kanury et al., ${ }^{12}$ the difference for the dispersion of the vapor between closed-cup and open-cup was to explain the reason why the two measurement devices yielded different flashpoint values. However, no quantitative reasoning was given to explain the difference between the trends of variation with pressure. Figure 7 indicates a possibility that the two lines may intersect at a sufficiently low pressure. Experimental studies at pressures even lower than that encountered in the current study are needed to test this hypothesis.

The regression coefficients and the correlation coefficients are listed in Table 3. The fitted values of the slope and intercept for the closed-cup flashpoint are seen to be in better agreement with the theoretical values than those for the open-cup flashpoint. Although from a fire safety point of view, the increased flammability limit at a lower pressure leads to a seemingly reduced 
Table 3. Theoretical and Fitted Values of the Slope and Intercept in Figure 7

\begin{tabular}{|c|c|c|c|c|c|c|c|c|}
\hline \multirow[b]{2}{*}{ fuel material } & \multicolumn{2}{|r|}{ theoretical values } & \multicolumn{3}{|c|}{ fitted values, closed cup } & \multicolumn{3}{|c|}{ fitted values, open cup } \\
\hline & slope $\left(-R / h_{f g}\right)$ & intercept $\left(1 / T_{1}+\ln P_{1} / m R / h_{\mathrm{fg}}\right)$ & slope & intercept & $R_{\mathrm{c}}$ & slope & intercept & $R_{\mathrm{c}}$ \\
\hline diesel & & & $-2.1 \times 10^{-4}$ & 0.011 & 0.989 & $-3.6 \times 10^{-4}$ & 0.016 & 0.988 \\
\hline Jet A & & & $-2.4 \times 10^{-4}$ & 0.012 & 0.994 & $-4.1 \times 10^{-4}$ & 0.018 & 0.992 \\
\hline hexanol & $-1.8 \times 10^{-4}$ & 0.009 & $-2.4 \times 10^{-4}$ & 0.011 & 0.995 & $-3.1 \times 10^{-4}$ & 0.014 & 0.963 \\
\hline decane & $-1.4 \times 10^{-4}$ & 0.007 & $-1.7 \times 10^{-4}$ & 0.009 & 0.992 & $-2.6 \times 10^{-4}$ & 0.122 & 0.984 \\
\hline
\end{tabular}

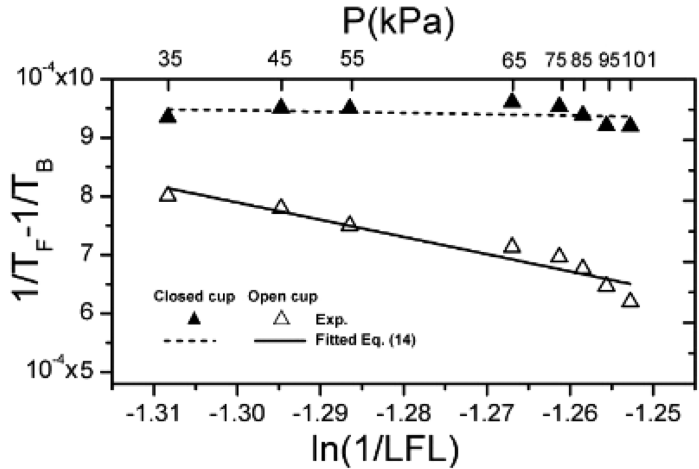

(a)

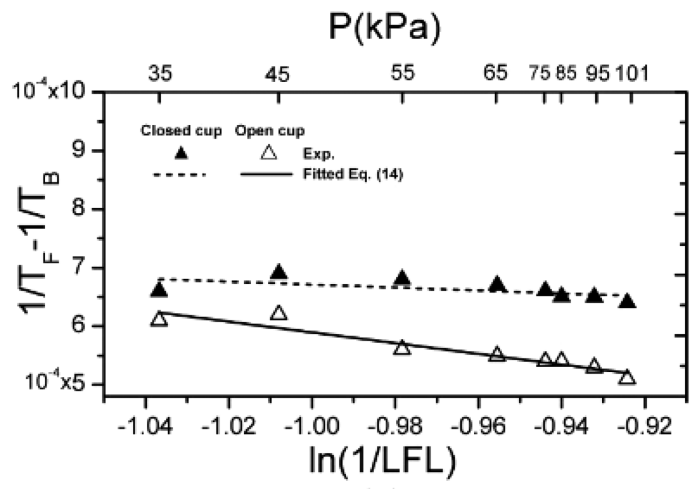

(c)

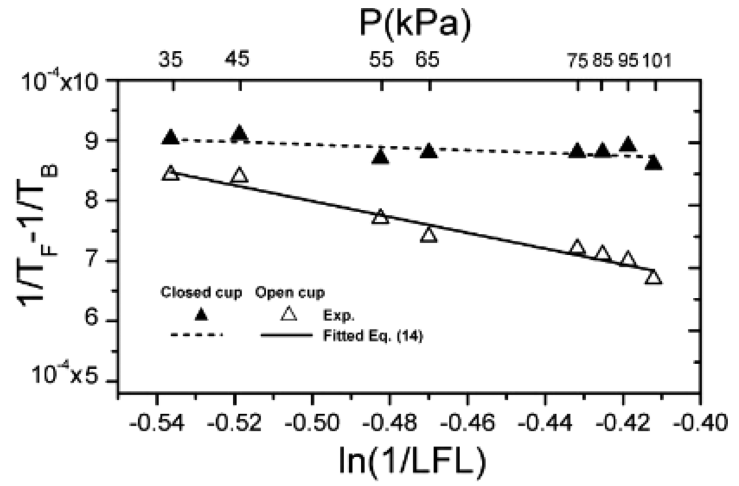

(b)

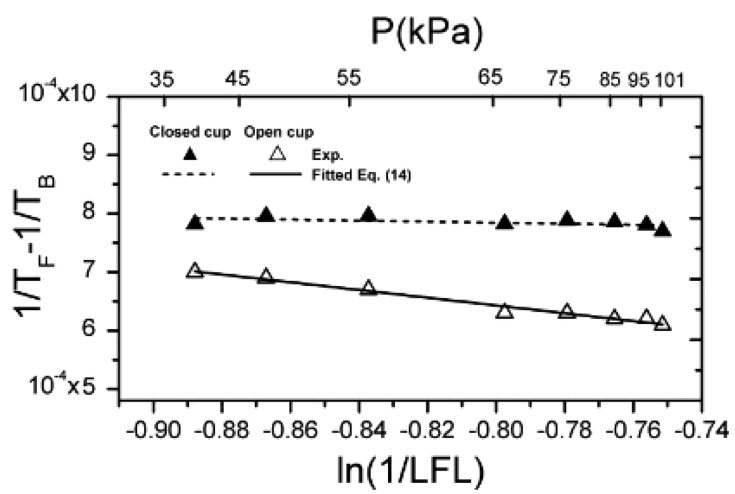

(d)

Figure 8. Flashpoint and boiling point versus the lower flammability limit at various pressures: (a) diesel, (b) Jet A, (c) hexanol, and (d) decane.

flammable fire ignition hazard (see section 3.2), a careful examination of Figure 6 reveals that at a reduced pressure the flashpoint of the liquid fuels investigated in the current study also decrease, leading to an earlier or easier attainment of the lower flammable limits and, hence, increased fire hazard on the contrary.

The results in Figure 7 and Table 3 reveal that, under the pressure range tested in the current study, both the closed-cup and open-cup flashpoints decrease with the decreasing of pressure. On the other hand, the decreasing rate of the closedcup flashpoint appears to be faster than that of the open-cup flashpoint. In other words, the difference between closed-cup and open-cup flashpoints becomes smaller as the pressure decreases and may eventually merge at a certain low pressure. As shown in Figure 7 and Table 3, the rates of change in closedcup and open-cup flashpoints at a given pressure within the pressure range of $35-101 \mathrm{kPa}$ both are different for the four fuels. The reason why there are different rates of change in closed-cup and open-cup flashpoints with pressure for the different fuels is the difference for the dispersion of the vapor.

\section{FURTHER ANALYSIS AND DISCUSSION}

5.1. Relationships among Boiling Point, Flashpoint, and Lower Flammability Limit. According to the research by Kanury et al., ${ }^{12}$ the relationships among the boiling point, the flashpoint (open-cup and closed-cup), and the lower flammability limit of the same fuel is

$$
\ln \frac{1}{\mathrm{LFL}}=\frac{h_{\mathrm{fg}}}{R}\left(\frac{1}{T_{\mathrm{F}}}-\frac{1}{T_{\mathrm{B}}}\right)+\ln K
$$

where $K$ is a constant that accounts for the fuel vapor dispersion, mass transfer in the apparatus, and the variability in the location at which the ignition source is presented in the mixture. Equation 13 has been validated for various liquid fuels at constant pressure. Assuming it is also applicable when pressure varies, eq 13 is rearranged such that it becomes

$$
\frac{1}{T_{\mathrm{F}}}-\frac{1}{T_{\mathrm{B}}}=\frac{R}{h_{\mathrm{fg}}} \ln \frac{1}{\mathrm{LFL}}-\frac{R}{h_{\mathrm{fg}}} \ln K=k \ln \frac{1}{\mathrm{LFL}}+b
$$

where $k$ and $b$ are coefficients. The notable observation from eq 14 is that the relationship between parameters $\left(1 / T_{F}-1 / T_{B}\right)$ and $\ln (1 / \mathrm{LFL})$ is linear.

Equation 14 is used to fit the measured data of $\left(1 / T_{\mathrm{F}}-1 / T_{\mathrm{B}}\right)$ versus $\ln (1 / \mathrm{LFL})$ for the four flammable liquids at different pressures in Figure 8 . It is seen that the experimental measurements confirmed the linear relationship. Since the 
closed-cup flashpoint was measured to be lower than its open-cup counterpart at any given pressure for the pressure range tested in the current study, the $\left(1 / T_{\mathrm{F}}-1 / T_{\mathrm{B}}\right)_{\text {closed-cup }}$ line is always above the $\left(1 / T_{\mathrm{F}}-1 / T_{\mathrm{B}}\right)_{\text {open-cup }}$ line in Figure 8 . Although the coefficient $k$ is a function of fuel property only and is independent of the experimental arrangement according to eq 14, the fitted lines of the experimental result in Figure 8 do exhibit different slopes for closed-cup and open-cup measurements.

Figure 8 also shows that the fire hazard classification of flammable liquids based on their flashpoints will increase with the decrease of pressure. However, if the lower flammability limit is used for the indicator of the fire hazard classification, the conclusion could be the opposite, because of the increase in LFL with decreasing pressure as shown in Figures 6 and 8. Therefore, the flashpoint, more specifically the closed-cup flashpoint, and flammable limit must be considered simultaneously in the fire hazard classification of flammable liquids at low pressure environments.

5.2. Application to Fire Hazard Classification Based on the Closed-Cup Flashpoint. According to the fire hazard codes, ${ }^{13}$ the fire hazard classifications of the four fuels are ranked for different pressure as shown in Figure 9.

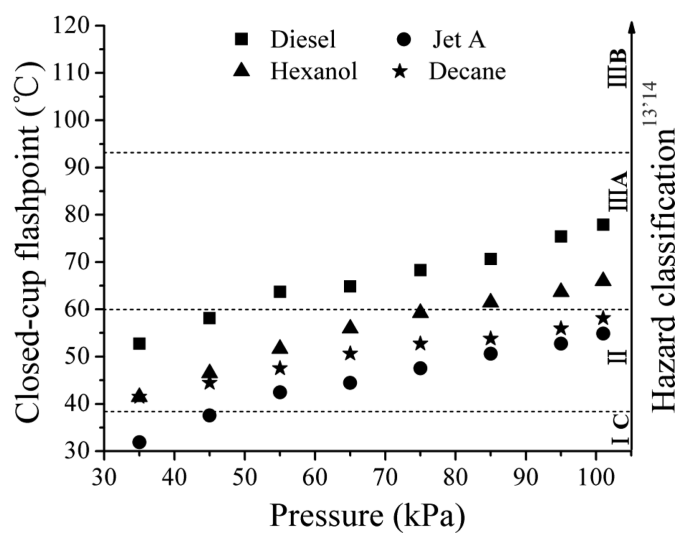

Figure 9. Closed-cup flashpoint and the fire hazard classification ranked for the four fuels at different pressures.

As shown in Figure 9, the fire hazard classification of the four fuels increases with the decreasing of pressure, and the decreasing rates become even higher under lower pressure. For example, the fire hazard classification of diesel changes from III A to II at the pressure of $47.5 \mathrm{kPa}$. For decane, its fire hazard classification remain at II under pressures ranging from 35 to $101 \mathrm{kPa}$, i.e., the fire hazard classification of decane maintains a relatively safe level over a wide pressure range. On the other hand, according to the storage requirements ${ }^{13}$ corresponding to different fire hazard classifications, the lower the flashpoint, the higher the requirements for the storage of flammable liquids. As a result, at lower pressures, the storage requirements become higher to achieve the objective of fire safety because of the decreasing of the closed-cup flashpoint. What's more, the stricter fire safety standards should be specified in designing the aircraft fuel tank.

\section{CONCLUSIONS}

This study measured and analyzed the boiling points, flashpoints, and LFLs of four flammable liquids at low pressures ranging from 35 to $101 \mathrm{kPa}$. Theoretical relations were derived and compared with the experimental data to reveal the pressure dependences of boiling points, flashpoints, and LFLs, as well as their relationships. The main conclusions are summarized as follows:

(1) The correlation between boiling point and ambient pressure established previously for pressures higher than standard atmospheric pressure was extended and validated in a wider range of low pressure conditions for four flammable liquids, which covers both single-component and multiplecomponent fuels. The generalization of the pressure dependence relationship for a wide range of pressures and liquid conditions is useful for fire safety classifications.

(2) Both the closed-cup and open-cup flashpoints decrease with decreasing pressure. However, the decreasing rate of the latter appears to be faster than that of the former. In other words, the difference between closed-cup and open-cup flashpoints becomes smaller as the pressure decreases and may eventually merge at a certain low pressure, which needs to be validated in a future study. If confirmed, a theoretical study is also warranted to explain this phenomenon.

(3) The lower flammable limits of the four fuel vapors were found to increase with decreasing pressure. Linear and third order polynomial correlations between the lower flammability limit and the pressure were compared well against the experimental data, while the third order polynomial correlation appears to have a better agreement.

(4) The relationship among boiling point, the flashpoint, and the LFL as proposed previously for standard atmospheric pressure was further validated for low pressures in this study. However, the sensitivity of the correlation coefficients on the experimental conditions requires further investigation.

Although the LFL of the fuels investigated increases with decreasing pressure, the fire hazard classification of those flammable liquids is still assumed to increases under lower pressures because of the decrease of the closed-cup flashpoint with pressure.

\section{APPENDIX: TABULATED MEASUREMENT RESULTS OF THE FOUR FUELS AT DIFFERENT PRESSURES}

Both the closed-cup and open-cup flashpoints decrease with decreasing pressure. The decreasing rate of the latter appears to

Table A1. Boiling Point

\begin{tabular}{|c|c|c|c|c|c|c|c|c|c|c|c|c|}
\hline \multirow{3}{*}{$\begin{array}{c}\text { pressure }(\mathrm{kPa}) \\
101\end{array}$} & \multicolumn{12}{|c|}{ boiling point $(\mathrm{K})$} \\
\hline & \multicolumn{3}{|c|}{ diesel } & \multicolumn{3}{|c|}{ Jet A } & \multicolumn{3}{|c|}{ hexanol } & \multicolumn{3}{|c|}{ decane } \\
\hline & 517.9 & 518.0 & 518.4 & 463.0 & 463.1 & 462.9 & 433.0 & 432.1 & 433.6 & 444.7 & 444.8 & 443.8 \\
\hline 95 & 512.0 & 513.2 & 513.2 & 458.9 & 458.6 & 458.6 & 430.0 & 431.2 & 431.9 & 442.0 & 442.9 & 443.5 \\
\hline 85 & 507.2 & 508.0 & 507.6 & 453.0 & 452.0 & 452.5 & 428.0 & 427.0 & 427.1 & 440.0 & 440.6 & 441.0 \\
\hline 75 & 505.0 & 504.5 & 506.3 & 446.8 & 446.0 & 446.4 & 426.0 & 425.0 & 425.6 & 439.1 & 438.0 & 437.3 \\
\hline 65 & 501.3 & 500 & 499.7 & 441.0 & 440.9 & 439.6 & 421.8 & 422.0 & 422.0 & 433.0 & 433.0 & 432.7 \\
\hline 55 & 495.0 & 495.6 & 494.4 & 435.0 & 435.0 & 434.4 & 417.0 & 417.0 & 416.0 & 431.3 & 431.0 & 430.8 \\
\hline 45 & 483.4 & 483.0 & 482.9 & 433.0 & 432.0 & 433.7 & 410.0 & 409.0 & 410.5 & 425.0 & 425.2 & 426.4 \\
\hline 35 & 467.8 & 467.4 & 466.7 & 420.0 & 421.0 & 420.5 & 396.8 & 397.0 & 396.6 & 416.0 & 416.5 & 417.5 \\
\hline
\end{tabular}


Table A2. Lower Flammability Limit

\begin{tabular}{|c|c|c|c|c|c|c|c|c|c|c|c|c|}
\hline \multirow{3}{*}{$\begin{array}{c}\text { pressure }(\mathrm{kPa}) \\
101\end{array}$} & \multicolumn{12}{|c|}{ lower flammability limit (\%) } \\
\hline & \multicolumn{3}{|c|}{ diesel } & \multicolumn{3}{|c|}{ Jet A } & \multicolumn{3}{|c|}{ hexanol } & \multicolumn{3}{|c|}{ decane } \\
\hline & 3.50 & 3.52 & 3.48 & 1.52 & 1.50 & 1.48 & 2.52 & 2.52 & 2.52 & 2.12 & 2.14 & 2.10 \\
\hline 95 & 3.50 & 3.50 & 3.50 & 1.50 & 1.52 & 1.54 & 2.54 & 2.54 & 2.54 & 2.14 & 2.14 & 2.14 \\
\hline 85 & 3.52 & 3.50 & 3.54 & 1.54 & 1.52 & 1.48 & 2.56 & 2.56 & 2.56 & 2.16 & 2.14 & 2.18 \\
\hline 75 & 3.54 & 3.54 & 3.54 & 1.56 & 1.54 & 1.52 & 2.58 & 2.58 & 2.58 & 2.18 & 2.16 & 2.20 \\
\hline 65 & 3.56 & 3.58 & 3.54 & 1.58 & 1.60 & 1.62 & 2.62 & 2.60 & 2.58 & 2.22 & 2.20 & 2.24 \\
\hline 55 & 3.62 & 3.64 & 3.60 & 1.62 & 1.62 & 1.62 & 2.66 & 2.66 & 2.66 & 2.30 & 2.30 & 2.30 \\
\hline 45 & 3.66 & 3.66 & 3.66 & 1.66 & 1.68 & 1.70 & 2.72 & 2.74 & 2.76 & 2.38 & 2.36 & 2.40 \\
\hline 35 & 3.70 & 3.68 & 3.72 & 1.68 & 1.70 & 1.72 & 2.82 & 2.80 & 2.84 & 2.44 & 2.44 & 2.44 \\
\hline
\end{tabular}

Table A3. Open-Cup Flashpoint

\begin{tabular}{|c|c|c|c|c|c|c|c|c|c|c|c|c|}
\hline \multirow{3}{*}{$\begin{array}{c}\text { pressure }(\mathrm{kPa}) \\
101\end{array}$} & \multicolumn{12}{|c|}{ open-cup flashpoint (K) } \\
\hline & \multicolumn{3}{|c|}{ diesel } & \multicolumn{3}{|c|}{ Jet A } & \multicolumn{3}{|c|}{ hexanol } & \multicolumn{3}{|c|}{ decane } \\
\hline & 392.3 & 392.0 & 392.3 & 353.0 & 354.5 & 353.7 & 354.7 & 354.0 & 355.1 & 350.5 & 349.2 & 349.4 \\
\hline 95 & 384.6 & 385 & 385.7 & 347.0 & 348.0 & 346.6 & 351.0 & 350.0 & 351.6 & 347.2 & 347.0 & 347.4 \\
\hline 85 & 377.6 & 378.0 & 378.1 & 342.1 & 342.0 & 343.4 & 347.3 & 347.0 & 347.4 & 346.0 & 346.2 & 345.8 \\
\hline 75 & 373.2 & 373.6 & 374.3 & 337.5 & 337.0 & 338.9 & 346.0 & 345.8 & 346.3 & 344.4 & 343.1 & 343.3 \\
\hline 65 & 368.7 & 368.0 & 369.1 & 332.2 & 332.3 & 332.1 & 342.3 & 342.6 & 342.5 & 340.0 & 341.0 & 339.3 \\
\hline 55 & 362.0 & 360.4 & 361.0 & 325.6 & 326.0 & 325.5 & 337.8 & 338.0 & 337.7 & 334.4 & 334.8 & 334.0 \\
\hline 45 & 351.0 & 351.3 & 349.7 & 318.0 & 317.5 & 317.0 & 326.9 & 326.4 & 327.1 & 329.0 & 328.6 & 329.1 \\
\hline 35 & 340.2 & 340.9 & 339.2 & 310.2 & 311.0 & 310.3 & 319.6 & 319.0 & 319.9 & 323.0 & 322.5 & 322.3 \\
\hline
\end{tabular}

Table A4. Closed-Cup Flashpoint

\begin{tabular}{|c|c|c|c|c|c|c|c|c|c|c|c|c|}
\hline \multirow[b]{2}{*}{ pressure $(\mathrm{kPa})$} & \multicolumn{12}{|c|}{ closed-cup flashpoint $(\mathrm{K})$} \\
\hline & \multicolumn{3}{|c|}{ diesel } & \multicolumn{3}{|c|}{ Jet A } & \multicolumn{3}{|c|}{ hexanol } & \multicolumn{3}{|c|}{ decane } \\
\hline 101 & 350.2 & 351.0 & 351.5 & 328.2 & 327.5 & 328.6 & 338.2 & 339.0 & 339.7 & 331.2 & 331.5 & 330.6 \\
\hline 95 & 348.9 & 348.2 & 348.1 & 325.8 & 326.0 & 325.3 & 336.3 & 336.9 & 336.9 & 328.5 & 328.8 & 329.4 \\
\hline 85 & 343.5 & 344.2 & 344.0 & 324.0 & 323.5 & 323.3 & 334.4 & 333.4 & 335.5 & 326.6 & 327.0 & 328.4 \\
\hline 75 & 341.0 & 340.8 & 341.2 & 320.0 & 321.0 & 320.5 & 332.0 & 333.0 & 331.7 & 326.0 & 325.4 & 326.3 \\
\hline 65 & 337.7 & 338.0 & 337.7 & 318.0 & 317.2 & 317.3 & 329.4 & 328.4 & 329.0 & 324.0 & 323.0 & 323.1 \\
\hline 55 & 336.7 & 336.0 & 337.4 & 315.8 & 316.0 & 314.7 & 324.7 & 324.3 & 325.0 & 320.6 & 321.0 & 321.0 \\
\hline 45 & 331.2 & 331.1 & 331.0 & 310.0 & 311.2 & 310.6 & 319.3 & 320.0 & 319.2 & 318.5 & 317.0 & 318.2 \\
\hline 35 & 325.6 & 325.0 & 325.3 & 304.7 & 305.0 & 304.7 & 314.2 & 314.0 & 315.2 & 314.2 & 315.3 & 313.4 \\
\hline
\end{tabular}

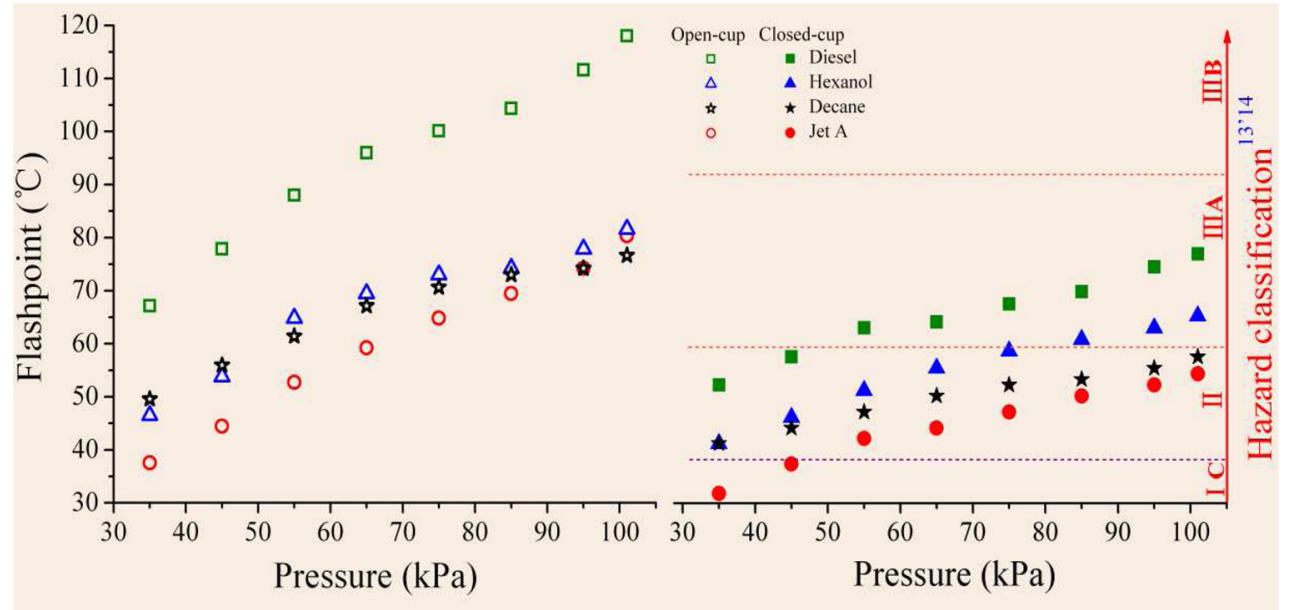

(a)

(b)

Figure A1. Open-cup and closed-cup flashpoints and the fire hazard classifications ranked for the four fuels based on the closed-cup flashpoint at different pressures.

be faster than that of the former. In other words, the difference between closed-cup and open-cup flashpoints becomes smaller as the ambient pressure decreases. According to the fire hazard codes, ${ }^{13}$ the fire hazard classification of the four fuels increases with decreasing pressure, and the decreasing rates become even higher under lower pressure. Accordingly, higher fire safety 
requirements should be specified for the storage of flammable liquids at lower pressure environments.

\section{AUTHOR INFORMATION}

\section{Corresponding Author}

*E-mail: wangj@ustc.edu.cn. Tel.: (+86) 55163606463.

\section{Notes}

The authors declare no competing financial interest.

\section{ACKNOWLEDGMENTS}

This research was financially supported by the National Natural Science Foundation of China (Grant No. 51376172). The authors also gratefully acknowledge G. Zhang for his hard work to machine the apparatus for measuring the LFL.

\section{NOMENCLATURE}

$C=$ number of carbon atoms in a hydrocarbon compound (-) $f=$ the fuel-air ratio $(-)$

$h_{\mathrm{fg}}=$ the latent heat of evaporation $\left(\mathrm{J} \cdot \mathrm{mol}^{-1}\right)$

$K=$ the constant that accounts for the fuel vapor dispersion and the variability constant $(-)$

$\mathrm{LFL}=$ the lower flammability limit (vol \%)

$M=$ the molecular weight $\left(\mathrm{g} \cdot \mathrm{mol}^{-1}\right)$

$n=$ mole number $(\mathrm{mol})$

$P=$ ambient pressure $(\mathrm{Pa})$

$P_{1}=$ fuel vapor pressure $(\mathrm{Pa})$ at standard temperature $T_{1}$ $(298 \mathrm{~K})$

$R=$ the molar gas constant $\left(8.314 \mathrm{~J} \cdot \mathrm{K}^{-1} \cdot \mathrm{mol}^{-1}\right)$

$R_{\mathrm{c}}=$ the correlation coefficient $(-)$

$T_{1}=$ standard temperature $(298 \mathrm{~K})$

$T=$ temperature $(\mathrm{K})$

\section{Subscripts}

air air

B boiling point

F flashpoint

fuel fuel

LFL at the lower flammability limit

\section{REFERENCES}

(1) Hu, X. K.; He, Y. P.; Li, Z. H.; Wang, J. Combustion Characteristics of $n$-Heptane at High Altitudes. Proc. Combust. Inst. 2011, 33, 2607-2615.

(2) Fang, J.; Tu, R.; Guan, J. F.; Wang, J. J.; Zhang, Y. M. Influence of low air pressure on combustion characteristics and flame pulsation frequency of pool fires. Fuel 2011, 90, 2760-2766.

(3) Kong, D.; Ende, D. J.; Brenek, S. J.; Weston, N. P. Determination of flashpoint in air and pure oxygen using an equilibrium closed bomb apparatus. J. Hazard. Mater. 2003, 102, 155-165.

(4) Shepherd, J. E.; Nuyt, C. D.; Lee, J. J. Flashpoint and Chemical Composition of Aviation Kerosene (Jet A); FM99-4; Explosion Dynamics Laboratory: Pasadena, CA, 2000; http://authors.library.caltech.edu/ 25832/.

(5) Shepherd, J. E.; Lee, J. J. Spark Ignition Measurements in Jet A: part II; FM 99-7; Explosion Dynamics Laboratory: Pasadena, CA, 2000.

(6) Nestor, L. J. Investigation of turbine fuel flammability within aircraft fuel tanks; DS-67-7; Naval Air Propulsion Test Center, Aeronautical Engine Department: Philadelphia, PA, 1967.

(7) Coward, H. F; Jones, G. W. Limits of flammability of gases and vapours; Bulletin No. 503; U.S. Bureau of Mines: Washington, DC, 1952.

(8) Lovachev, L. A. Flammability limit: an invited review. Combust. Flame 1973, 20, 259-289.
(9) Liu, X.; Zhang, Q. Influence of initial pressure and temperature on flammability limits of hydrogen-air. Int. J. Hydrogen Energy 2014, $39,6774-6782$.

(10) Vanderstraeten, B.; Tuerlinckx, D.; Berghmans, J.; Vliegen, S.; Van't Oost, E.; Smit, B. Experimental study of the pressure and temperature dependence of the upper flammability limit of methaneair mixtures. J. Hazard. Mater. 1997, 56, 237-246.

(11) Van den Schoor, F.; Verplaetsen, F. The upper flammability limit of methane/hydrogen/air mixtures at elevated pressures and temperatures. Int. J. Hydrogen Energy 2007, 32, 2548-2552.

(12) Kanury, A. M. A relationship between the boiling point, flashpoint and the lean limit of flammability of liquid fuels. Combust. Sci. Technol. 1983, 31, 297-302.

(13) NFPA 30. Flammable and Combustible Liquids Code; National Fire Protection Association: Quincy, MA, 2012.

(14) Ding, C.; Yao, W.; Zhou, D.; Rong, J.; Zhang, Y.; Zhang, W.; Wang, J. Experimental study and hazard analysis on the flash point of flammable liquids at high altitudes. J. Fire Sci. 2013, 31, 469-477.

(15) Prasad, K.; Li, C.; Kailasanath, K.; Ndubizu, C.; Ananth, R.; Tatem, P. A. Numerical modelling of methanol liquid pool fires. Combust. Theor. Model. 1999, 3, 743-768.

(16) Reynolds, W. C.; Perkins, H. C. Engineering thermodynamics, 2nd ed.; McGraw-Hill: New York, 1977.

(17) Iglesias, M.; Orge, B.; Marino, G.; Tojo, J. Vapor-liquid equilibria for the ternary system acetone+methanol+water at 101.325 kPa. J. Chem. Eng. Data 1999, 44, 661-665.

(18) ASTM D 93. Standard test methods for flash point by PenskyMartens closed cup tester; American Society for Testing and Materials: West Conshohocken, PA, 2002.

(19) ASTM D 92. Standard test method for flash and fire points by Cleveland open cup; American Society for Testing and Materials: West Conshohocken, PA, 2002.

(20) EN 1839. European Committee for Standardazation, Determination of explosion limits of gases and vapours; European Committee for Standardazation: Brussels, 2003. 